\title{
O Hades de Gil Vicente e de Aristófanes, no Auto da Barca do Inferno e nas Rãs, comparado ao de Platão, na República
}

Ana Maria César Pompeu ${ }^{1}$

http://lattes.cnpq.br/4726092826722326

Enviado em: 31/08/2018

Aceito em: 20/11/2018

\begin{abstract}
RESUMO: No Auto da Barca do Inferno, há duas barcas, a do Paraíso e a do Inferno, pilotadas, respectivamente, por um Anjo e por um Demônio, dividindo o destino de justos e injustos. Em As Rãs, há também a dicotomia de justos e injustos no Hades bem representada na divisão do coro em Iniciados e Rãs. Os primeiros colocados em um lugar de luz, junto ao deus Plutão, enquanto os outros estão atolados no pântano. Na República, há a mesma representação e há também a coincidência de termos que descrevem o Hades com os empregados por Aristófanes na mesma descrição. Há ainda em Aristófanes a dicotomia de justiça e injustiça representada pela disputa entre os poetas trágicos Ésquilo e Eurípides, respectivamente. Os dois poetas de gêneros cômicos e o filósofo coincidem na divisão de justos e injustos no mundo dos mortos.
\end{abstract}

Palavras-chave: Hades; Gil Vicente; Aristófanes; Platão.

ABSTRACT: In the Auto da Barca do Inferno, there are two boats, the one of the Paradise and the one of the Hell, piloted, respectively, by an Angel and a Demon, dividing the destiny of just and unjust. In The Frogs, there is also the dichotomy of the just and unjust in Hades well represented in the division of the choir in Initiates and Frogs. The first placed in a place of light, next to the god Pluto, while the others are mired in the swamp. In the Republic, there is the same representation and there is also the coincidence of terms describing the Hades with those employed by Aristophanes in the same description. There is still in Aristophanes the dichotomy of justice and injustice represented by the quarrel between the tragic poets Aeschylus and Euripides, respectively. The two poets of comic genres and the philosopher coincide in the division of the just and unjust into the world of the dead.

Keywords: Hades; Gil Vicente; Aristophanes; Plato.

Rãs é a única peça de Aristófanes em que há dois coros que não se opõem, como acontece com os dois semicoros de Lisistrata ou com o coro de Acarnenses. E ela recebe o nome não do coro principal, de iniciados, mas do coro de rãs, que só se manifesta durante a travessia do pântano por Dioniso, no barco de Caronte. Strauss (1993, p. 304) sugere que essa dualidade coral corresponde à dualidade de terror e felicidade no Hades. O coro de rãs toma, assim, o lugar dos criminosos extremados no Hades, que são os adoradores de Eurípides, como percebemos pela descrição de Éaco, escravo de Plutão (vv. 771 ss):

Éaco. Quando Eurípides chegou, deu um espetáculo aos ladrões de roupa, aos batedores de carteira, aos parricidas e aos arrombadores que, aqui no Hades, formam uma multidão. E eles, assistindo às discussões, às negaças e às viradas, ficaram completamente loucos por ele que, então, foi considerado o mais

\footnotetext{
1 Docente do Programa de Pós-Graduação em Letras: Literatura Comparada e do Departamento de Literatura da Universidade Federal do Ceará.

E-mail: amcpompeu@hotmail.com
}

https://periodicos.unifap.br/index.php/letras

Macapá, v. 9, n. 1, $1^{0}$ sem., 2019 
Esses criminosos não teriam sido suportados como um coro que professa os mais altos princípios de injustiça, sem conversão, mesmo com os castigos após a morte. Assim, o título da peça nos faz notar essa "impossibilidade potencial" (Strauss, 1993, p. 304).

Gil Vicente, no Auto da Barca do Inferno, representado pela primeira vez em 1517, apresenta uma duplicidade semelhante a da comédia aristofânica As Rãs. As almas chegam para embarcar ao inferno ou ao paraíso:

a discriminação vem representada pelas duas barcas que se encontram no porto alegórico. Uma, guiada por um anjo, tem a finalidade de levar aquelas almas que, segundo a religião vigente, são dignas do paraíso. A outra, guiada por um Diabo, tem a finalidade de levar aqueles que são caracterizados como impuros. (SALES, 2016, p.132)

Como em Aristófanes, a maioria das almas é condenada: o Fidalgo arrogante, que representa a Aristocracia; o Onzeneiro, um agiota, que empresta dinheiro a juros altíssimos; o Sapateiro, que representa os comerciantes que enganavam as pessoas; o Frade com sua amante, representado o clero corrupto; a Alcoviteira, que prostitua as jovens; o Judeu, que era visto com preconceito religioso, na época, como responsável pela morte de Jesus; o Corregedor e o Procurador, que representam a corrupção jurídica; o Enforcado, que se julgava salvo pela sua morte na forca (TUFANO, 2006, p.11).

Os que se salvam são o Parvo, camponês ignorante e explorado, mas que não apresenta malícia, e os quatro Cavaleiros, que morreram nas Cruzadas em defesa do Catolicismo.

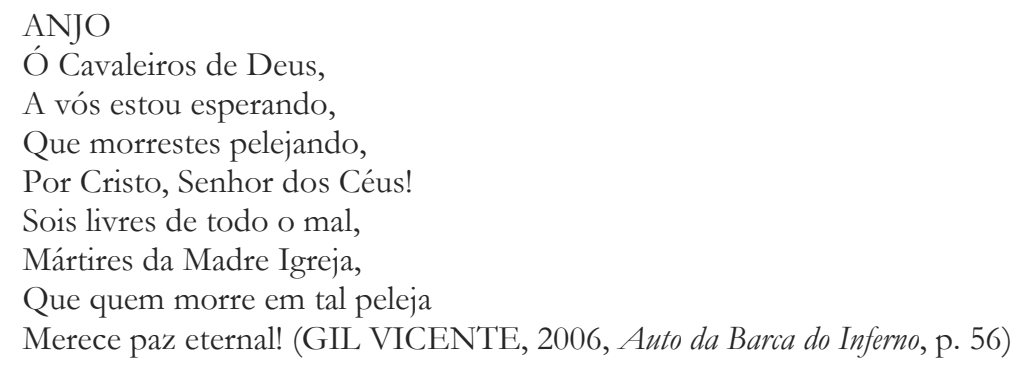

Na comédia As Rãs, Ésquilo foi escolhido por Dioniso, que, em princípio, desejava ardentemente Eurípides, para voltar à vida e salvar a cidade. As diferenças entre os dois poetas são bem marcadas na peça.

a) Eurípides introduz novas divindades e, implicitamente, contesta as estabelecidas (885-94):

Dioniso (aos poetas) E vocês aí façam uma oração antes de recitarem os versos!

Ésquilo Deméter, que alimentaste o meu espírito, que eu seja digno de vossos mistérios!

Dioniso (a Eurípides) E você toma o incenso e ofereça-o!

Eurípides (recusando o incenso) Obrigado! São outros os deuses a quem dirijo as minhas preces...

Dioniso São deuses só seus, de nova cunhagem?

Eurípides São sim.

Dioniso Vamos! Reze então a esses seus deuses!

Eurípides Éter, meu alimento! Móvel de minha língua! Conhecimento! Narinas sagazes! Que eu refute à altura os discursos que vou enfrentar!

2 Tradução inédita da Ana Lia de Almeida Prado e Silvia Milanezi. 
Podemos encontrar um outro aspecto da impiedade de Eurípides em Tesmoforiantes $451 \mathrm{s:}$ "Mas agora esse fulano, que trabalha em tragédias, convenceu os homens de que não há deuses."

b) A poesia de Ésquilo imita a natureza, por isso se interessa principalmente pela ética do seu conteúdo; a de Eurípides imita a imitação da natureza, por isso se interessa, primeiro, pela técnica poética, pelo realismo de seu discurso. Desse modo, Ésquilo apresenta personagens nobres, com linguagem e trajes adequados; enquanto Eurípides apresenta personagens mais próximos da realidade, e, assim, defeituosos, com linguagem e trajes correspondentes (Santos, 1992/3, pp. 83-95). Eurípides fala da inutilidade da linguagem pomposa de Ésquilo, que se defende, dizendo que:

Esq. É preciso criar falas à altura dos grandes provérbios e pensamentos. Aliás, é de se esperar que os semideuses usem falas mais imponentes, pois também usam mantos muito mais imponentes que os nossos. O que eu apresentei como útil você destruiu.[...] Primeiro vestiu os reis com farrapos para que os homens parecessem dignos de piedade... Depois você ainda os ensinou a entregar-se à tagarelice e ao falatório, o que esvaziou as palestras, poliu a bunda dos mocinhos tagarelas e convenceu o pessoal do porto a contestar os chefes. ... De que males não é culpado? Esse aí não pôs em cena alcoviteiras, mulheres que dão à luz nos templos, que se unem com irmãos, que dizem que viver não é viver? É por isso que a cidade ficou cheia de escrevinhadores, de bufões, macacos do povo, que ao povo estão sempre enganando. Tocha ninguém é capaz de levar, hoje em dia, por falta de exercício. (ARISTÓFANES, $A s$ Rãs, vv. 1059-89)

Ésquilo acusa Eurípides do mesmo crime de que Dikaios Logos tinha acusado o Adikaios Logos, em Nuvens: fazer com que os cidadãos se ocupem mais de falar do que de praticar ginástica. E também de misoginia e falar mal das mulheres, de que ele é acusado em Tesmoforiantes e Lisistrata. Em Nuvens, Fidípides começa a bater no seu pai por que ele o impede de recitar passagens de Éolo de Eurípides, cujo tema é incesto entre irmãos. Assim como o Sócrates de Nuvens se distinguia dos dois discursos, o justo e o injusto, Dioniso e Aristófanes se diferenciam dos dois poetas, Ésquilo e Eurípides. Pois enquanto Ésquilo não cuida de Afrodite e da compaixão, Eurípides descuida da cidade ou do patriotismo guerreiro e de esconder uma verdade perniciosa. Strauss chama a atenção para a função edificante, representada por Ésquilo, e a corretiva do riso, de que se ocupa Aristófanes, e da compaixão, atribuída a Eurípides. Bowie, em seu livro Aristophanes Mith, ritual and comedy, no capítulo dedicado à peça Tesmoforiantes, sugere que Aristófanes delimita a tragédia de Eurípides, que teria incorporado traços cômicos especialmente nas duas peças mais recentes: Helena e $A n$ drômeda.

No Hades, de modo diferente de Atenas, são os melhores poetas que ocupam lugar de destaque junto a Plutão. Assim, em analogia a Atenas, que dá a proedria e o alimentar-se no Pritaneu como honras a um benfeitor da pólis, podemos concluir que o bom poeta é um benfeitor tanto para a cidade de um modo geral como para a alma humana. Dioniso é competente para julgar o melhor poeta trágico, então também o seria para julgar a sabedoria política. Ele pune com justiça Eurípides por sua negação dos deuses dando o prêmio para Ésquilo. Age semelhante às Nuvens: com justiça (Nuvens 1462). A peça Rãs apresenta a educação de Dioniso, o educador de Aristófanes, que vai da admiração sem limite por Eurípides a uma preferência por Ésquilo. Tal educação se dá em um Hades inteiramente ateniense. O coro, no final da peça, parece fazer uma equivalência entre Eurípides e Sócrates, contrastando este último com Ésquilo. Ao rejeitar o que é das Musas, o Sócrates de AsRãs, equipara-se ao de Nuvens, onde é representado em um Pensatório que se assemelha ao Hades. 
Coro. Bem aventurado o homem

que tem inteligência precisa.

Muitos exemplos há para aprendermos isso.

Este homem mostrou que é sensato

e volta a casa outra vez,

para o bem dos cidadãos,

para o bem dos seus,

dos parentes e amigos,

porque é inteligente.

A alegria não é, ao lado de Sócrates

ficar sentado, conversando,

rejeitando o que é das Musas,

deixando o que há de melhor

na arte da tragédia.

Com palavras pomposas,

com sutilezas de tagarelice

gastar o tempo à toa

é próprio do insensato.

A descida de Dioniso ao mundo dos mortos torna esta peça uma das três, dentre as que nos restam de Aristófanes, a trazer uma viagem ao além. Os outros dois casos: de Trigeu, em Paz, e de Pisetero e Evélpides, em Aves, são homens do povo que se elevam a uma condição superior. Em As Rãs, é o deus do teatro que realiza essa proeza, e dessa vez não é uma subida, mas uma descida ao Hades. Mas nem mesmo o deus escapa dos temores aos horrores das regiões ínferas. Ele necessita de um disfarce de coragem: o de Heracles, que já havia estado lá, para capturar o cão Cérbero e também para trazer de volta a rainha Alceste, registrada na tragédia homônima de Eurípides, de onde, certamente, Aristófanes retira a inspiração do disfarce de Dioniso. Duchemin compara a descida de Dioniso em $A s$ Rãs a passagens na Epopeia de Gilgamesh e à Descida de Ishtar aos infernos. É que, segundo a autora, apesar do tom diferente da comédia de Aristófanes ao da epopeia babilônica, não parece haver na literatura grega algo semelhante aos episódios da viagem do deus do teatro à mansão de Hades.

Heracles Mas a travessia é longa [...]. Logo você chegará a um pântano enorme (limênmegalên), um abismo profundo. [...] Numa barquinha deste tamanhinho, um velho, um marinheiro, conduzirá você pelo preço de dois óbolos [...]. Teseu os levou. Depois disso você vai ver cobras e bichos, aos milhares, horripilantes (opheiskaitheri' opseimyriadeinotata)! [...] Depois vai ver um grande pântano e bosta que não seca nunca. Lá está quem um dia maltratou um hóspede, quem trepou com menino e não pagou, quem matou a mãe, e quem deu um soco no queixo do pai, quem quebrou um juramento ou quem tirou cópia de uma tirada de Mórsino!

Dioniso Pelos deuses! Também deveriam colocar nesse bolo quem ensinou a pírrica a Cinésias.

Heracles Ali um sopro de flautas vai envolver você. Vai ver uma luz lindíssima como as daqui, bosques de mirto, alegres tíasos de homens e mulheres. Vai ouvir também muitas palmas...

Dioniso E esses, quem são?

Heracles Os iniciados. [...] Eles vão indicar a você tudo o que for preciso, porque moram logo à beira do caminho, bem junto à porta de Plutão. (137ss).

A aparição de Empusa, uma espécie de assombração, imediatamente anterior à dos iniciados, como a passagem súbita do desespero à esperança, é interpretada como integrante dos Mistérios Eleusinos. Bowie afirma que o coro de iniciados de As Rãs é realmente composto de Iniciados Eleusinos que, tendo atingido a felicidade póstuma prometida por sua iniciação, continuam a praticar uma forma de seu culto. 
Coro: Fique em silêncio e ceda lugar aos nossos coros quem é inexperiente em tais palavras ou não tem pura a mente, ou nunca viu ou dançou a orgia das nobres Musas, nem foi iniciado nos cantos báquicos da língua de Cratino Come-touro, mas se alegra com versos bufos ditos fora de hora, quem à odiosa guerra civil não põe fim nem é bem disposto com os cidadãos, mas a desperta e a atiça, desejando o próprio lucro ou quando a cidade é açoitada por uma tempestade, sendo arconte, se deixa subornar [...] - que cedam lugar aos coros dos iniciados. E vocês, iniciados, renovem o canto e as nossas vigílias, como convém a esta festa. (AsRãs vv. 354-71)

Em Platão, temos a mesma ideia da iniciação nos Mistérios como a libertação dos males: os iniciados são salvos, enquanto que os não iniciados jazem em um lodaçal. Em Fédon, o filósofo é o verdadeiro iniciado.

Sócrates É provável, pois, que os fundadores dos nossos ritos mistéricos não fossem homens medíocres, antes pelo contrário, desde há muito nos sugerissem a verdade, ao asseverar que todo aquele que chega ao Hades sem ter sido iniciado há de jazer na lama, enquanto aquele que vai purificado e iniciado habitará, ao lá chegar, na companhia dos deuses. É que, como dizem os entendidos nos Mistérios, "muito são os portadores de tirso, mas poucos os bacantes". Ora, estes últimos quer-me parecer que não são outros senão os que se consagraram, no verdadeiro sentido da palavra, à filosofia. (Fédon $69 \mathrm{c}$ - d).

Sócrates Ora isso é o que chamam iniciação, que nos liberta dos males no além, ao passo que a quem não executar esses sacrifícios, terríveis desgraças o aguardam. (Rép. 365 a).

Em As Rãs temos ainda a referência a Museu e Orfeu como poetas que ensinaram coisas úteis, como os Mistérios e os oráculos (v. 1030 ss):

Esquilo [...] Observe que, desde o princípio, foram úteis os poetas nobres. Orfeu ensinou os mistérios e como abster-nos de assassínios; Museu, a cura das doenças e os oráculos; Hesíodo, o trabalho dos campos, as estações dos frutos e o preparo da terra. E o divino Homero, por que obteve fama e glória? Não foi por que ensinou coisas úteis à linha de combate, virtudes e armas dos homens?

$\mathrm{Na}$ República também podemos ler a referência aos dois poetas em contextos, que mostram os ensinamentos de Museu e Orfeu (363 c - d; 364 e - 365 a), primeiro as afirmações daqueles que amam a justiça e louvam-na pela boa fama e pelos numerosos bens, que dizem que os deuses outorgam aos justos; depois as dos que acreditam que os próprios deuses atribuíram aos homens honestos uma vida desgraçada, ao passo que aos maus, o contrário:

\begin{abstract}
Adimanto Museu e seu filho outorgam aos justos, por parte dos deuses, bens ainda mais esplendorosos do que estes. Efetivamente, levam-nos em imaginação ao Hades, instam-nos à mesa, preparam-lhes um banquete dos bem-aventurados, coroando-os de flores, e fazem-nos passar todo o tempo, daí em diante, a embriagar-se, imaginando que o mais famoso salário da virtude é uma embriaguez perpétua. Outros alongam ainda mais do que estes os benefícios por parte dos deuses, pois afirmam do homem puro e fiel aos seus juramentos permanecem os filhos dos filhos e a raça vindoura. São estes e outros elogios no gênero os que fazem à justiça. Quanto aos homens ímpios e injustos, esses, pelo contrário, enterram-nos no lodo do Hades, e obrigam-nos a transportar água num crivo, e ainda em vida lhes imputam má fama. Adimanto Além disso, apresentam um monte de livros de Museu e Orfeu, filhos da Lua e das Musas, ao que dizem. É por eles que executam os sacrifícios, persuadindo não só particulares, como também cidades, de que é possível a libertação e purificação dos crimes por meio de sacrifícios e de folguedos aprazíveis, quer em vida, quer depois da morte. Ora isso é o que chamam iniciação, que nos liberta dos males no além, ao passo que a quem não executar esses sacrifícios, terríveis desgraças o aguardam.
\end{abstract}

Há, na peça, o emprego das palavras mystikotatos(314) e memyemenoi ('iniciados’318) em um contexto contendo Iaco, mencionado quatorze vezes em cem linhas, que era uma divindade cuja estátua, coroada com mirto (330) e acompanhada por tochas $(313,340)$, estava na procissão que ia de Atenas a Elêusis.O prado (326) é uma peça padrão da geografia eleusina dos ínferos; Xântias sente cheiro de carne de porco (338), e o porco, regularmente 
sacrificado a Deméter, desempenhava uma função importante nos ritos de Elêusis. Há ainda uma referência da proclamação das restrições (prorrhesis) dos Mistérios em 354 ss.

Em Platão, lemos diversas referências aos Iniciados nos Mistérios como representação da justiça e da felicidade do justo:

Sócrates Porém a beleza era muito fácil de ver por causa do seu brilho peculiar quando, no séquito de Zeus, tomando parte no coro dos bem-aventurados e os demais no de outra divindade, gozávamos do espetáculo dessa visão admirável e, iniciados nesse mistério que, com toda a justiça, pode ser denominado sacratíssimo, e que celebrávamos na plenitude da perfeição e livre dos males que nos alcançam no futuro, fomos admitidos a contemplar sob a luz mais pura aparições perfeitas, simples, imutáveis, puros também e libertos deste cárcere de morte que com o nome de corpo carregamos conosco e no qual estamos aprisionados como a ostra em sua casca. (Fedro, 250 b-c).

Sócrates Depois de terem esvaziado e purificado a alma do jovem por elas possuído e de a terem iniciado nos Grandes Mistérios, logo a seguir trazem, na companhia de um numeroso coro, a insolência, anarquia, a prodigalidade e a desfaçatez, todos resplandecentes, de cabeças coroadas; fazem o seu elogio e chamamlhes nomes bonitos, designando a insolência por boa educação, a anarquia por liberdade, a prodigalidade por generosidade, a desfaçatez por coragem. (República $560 \mathrm{~d}-\mathrm{e}$ )

A presença da bem-aventurança, para os justos, e dos castigos, para os ímpios, no Hades, ou no além, está bem marcada em Platão. Os textos sobre a morte e o destino das almas depois dela são numerosos e complementares na obra desse filósofo. Estão em dois diálogos relacionados à morte de Sócrates: Apologia e Fédon, e três mitos sobre esses temas encerram, respectivamente, Górgias, Fédon e República. Há ainda a narrativa mítica da vida celeste das almas antes de sua reencarnação, no Fedro.

No mito de Górgias, por exemplo, há o prado (524 a), no qual se situa a bifurcação, de onde dois caminhos distintos levam as almas, ou ao Tártaro, ou às Ilhas dos Bem-aventurados. Um prado (leimôn) faz parte também da mansão dos iniciados em As Rãs (326, 344, 373-4, 448-9). Por conseguinte, o prado fazia parte do núcleo tradicional das representações do além. No mito de Er, na República, o primeiro local designado é chamado de topon tina daimonion $(614 \mathrm{c})$, junto dele encontram-se as almas num prado (leimôn614 e, 616 b). É ali que estão os juízes e que se vêem duas aberturas em baixo e duas em cima (614 c). Aberturas essas para ir ou vir da terra, para ir ou vir do céu, respectivamente. Uma vez que o seu destino fora confirmado pelas Moiras e retificado por Anagke, as almas seguiam para o Lêthêspedion(621 a), onde bebiam do rio Ameles e adormeciam. Após a meia-noite, eram despertos por um trovão e um tremor de terra e fugiam como estrelas. O lêthêspedion, com relação aqui à metempsicose, não era novo na literatura grega, é citado por Aristófanes entre as localidades do Hades em Rãs 186. Platão aplica o mesmo nome ao próprio rio, por extensão.

Em As Rãs temos a referência clara sobre a parte séria da comédia, cantada pelo coro de iniciados, ao louvar a deusa Deméter (vv. 386-95 negrito nosso):

Coro.

Deméter das santas orgias a rainha sê nossa madrinha, salva o coro que é teu.

Que eu, em segurança, o dia todo

Brinque e dance!

Que eu diga muitas palavras engraçadas

E muitas palavras sérias!

E, como a sua festa merece, 
Brincando e zombando,

Tenha a vitória e as fitas!

Vamos! Agora com cantos chamai aqui o jovem deus,

Nosso companheiro nesta dança!

\section{Conclusão}

É interessante notarmos que Aristófanes está sempre requisitando para a sua comédia o reconhecimento da justiça de seus conselhos, seja nas parábases, através do coro, ou em outras partes, através de um porta-voz do poeta. Platão parece alvejar Aristófanes, especialmente em As Rãs, ao apresentar, no início da República, as referências aos poetas Museu e Orfeu, Homero e Hesíodo, como apologistas da justiça por suas recompensas e do poder das iniciações nos Mistérios para a salvação das almas; e, ainda mais, ao rejeitar, no livro X, os conselhos dos poetas, representados por Homero, por estes estarem distantes três graus da verdade e não serem responsáveis pela melhora dos cidadãos e, consequentemente, das cidades. Sócrates afirma que é antiga a rivalidade entre poesia e filosofia e cita passagens que, geralmente são atribuídas a obras cômicas.

As representações teatrais na Idade Média se vinculavam fortemente às cerimônias religiosas católicas, celebradas dentro das igrejas, nas datas comemorativas, como a Páscoa e o Natal:

\footnotetext{
Representavam-se assim os mistérios e milagres (peças que tratavam da história de Cristo, de episódios da Bíblia ou da vida de santos), e as moralidades (peças de claro simbolismo moral, em que as personagens pecadoras sofriam terríveis punições, que apavoravam e alertavam os espectadores sobre os perigos do $\mathrm{Mal})$.

Com o tempo, os espetáculos começaram a tratar também de outros temas, fora do campo estritamente religioso. Nasceram assim as farsas, que eram peças satíricas que divertiam muito o público.

Genericamente, essas peças medievais são chamadas de autos. Conforme define o crítico Massaud Moisés: "Vinculado aos mistérios e moralidades, e talvez deles proveniente, o auto designa toda peça breve, de tema religioso ou profano, em circulação durante a Idade Média". (TUFANO, 2006, p.7. Negrito nosso)
}

Nos livros II e III, Platão apresenta os critérios éticos a que devem se submeter os poemas que serão apresentados às crianças e jovens, como primeira forma de educação. E submete a tais critérios todas as técnicas poéticas. O cômico de Aristófanes e Gil Vicente se mostra preocupado com o objeto de sua poesia, de modo a privilegiar os princípios éticos.

\section{Referências}

DUCHEMIN, Jacqueline. "Recherche sur un thème aristophanien et ses sources religieuses: les voyages dans l'autre monde". Les Études Classiques, tome xxv n. 3, 1957, pp. 273295.

POMPEU, Ana Maria César. Aristófanes e Platão: a justiça na pólis. São Paulo: Editora 24 Horas, 2011.

PLATÃO. A república. Introdução, tradução e notas de Maria Helena da Rocha Pareira.

7a. ed. Lisboa: Fundação Calouste Gulbenkian, 1993. . Diálogos: Fedro, Cartas, O primeiro Alcibiades. Tradução Carlos Alberto Nunes. V.

5. Universidade Federal do Pará, 1975. 
Górgias. Introdução, tradução do grego e notas de Manuel de Oliveira Pulquério. Lisboa: Edições 70, 1991.

PRADO, Ana Lia de Almeida; MILANEZI, Silva Sueli.Tradução inéditad'As Rãs de Aristófanes.

SALES, KallLyws Barroso. Reflexões sobre a Barca no Teatro Vicentino: aspecto residual da Comédia Aristofânica. Revista Diálogos Acadêmicos, Fortaleza, v. 5, n. 2, jul./dez. 2016, pp.130-133.

SANTOS, Marcos Martinho dos. A teoria literária aristofânica. Clássica 5/6, São Paulo, 1992/1993, pp. 83-95.

STRAUSS, Leo. Socrate ET Aristophane. Traduit de l'a anglais et présenté par Olivier Sedeyn. LeÉclat, 1993. (Collection "Polemos"), (1ª edição 1966).

TUFANO, Douglas. Auto da barca do inferno/ Gil Vicente Texto integral acompanhado de uma adaptação em português moderno de Douglas Tufano. São Paulo: Editora Moderna, 2006. (Coleção Travessias) 